\title{
Modeling the balance of interests of the participants of an investment and construction project in the context of the use of BIM technologies
}

\author{
Lyudmila Oparina, and Ivan Karasev * \\ Ivanovo State Polytechnic University, 153000, Ivanovo, Russia
}

\begin{abstract}
One of the most urgent areas of development of the construction industry is the introduction of BIM technologies in investment and construction projects. Nowadays, despite the active development of software, the issues of providing a regulatory and legal framework for the implementation of BIM technologies in the organization and management of investment and construction projects, as well as regulations for the interaction of participants both at the design and construction stages, remain insufficiently resolved. The issue of assessing the effectiveness of BIM implementation also remains relevant. To solve the above issues, it is advisable to model the balance of interests between the participants, since they often pursue multidirectional goals. Based on the analysis of modern modeling methods that allow describing the multidirectional interests of participants in investment and construction projects, the authors came to the conclusion that it is advisable to use the methodological apparatus of game theory. Also, it is possible to use the Nash equilibrium method, which, when applied to the organization of investment and construction projects, can be formulated as follows: all participants achieve the observance of their interests (win) without colluding. The systematic application of BIM technologies together with the balance of interests of the participants in investment and construction projects will increase the efficiency of their organization and management.
\end{abstract}

\section{Introduction}

The use of BIM technologies is currently an integral part of the design, construction and operation of buildings. And this is not only 3D-modeling. It is information bases and calculations of the full life cycle of an object: from design to disposal [1]. Building information modeling (BIM) does not lose its relevance and is an important part of the digitalization process of the construction industry, and it is used both in the operation and in the reconstruction of industrial and civil buildings. According to modern Russian standards (GOST R 21.101.2020, Article 57.5 of the Civil Code of the Russian Federation), "The information model of a construction object is a set of documents, graphic and non-graphic data on a

*Corresponding author: van_ok93@mail.ru 
construction object submitted in electronic form, placed in the environment of general data in accordance with the established rules, which is a single reliable source of information on an object at all or individual stages of its life cycle".

The construction industry is currently undergoing a period of significant reforms associated with both the reforms of the pricing system, project management, and the introduction of information modeling. Along with federal laws that generally reform the construction industry, two federal laws were signed that are responsible for the procedure for the reform of pricing (FZ-368 and FZ-369). There have appeared such types of project documentation as project documentation for re-use, cost-effective design documentation, which contain criteria for economic efficiency. Modern construction is impossible without modern software: planning and implementation of works, risk assessment, the possibility of obtaining aerial photographs, online monitoring of construction sites using live broadcasts and 3D visualization are currently irreplaceable technologies in construction. The implementation of BIM is aimed at a qualitative transformation of the construction industry through digital technologies.

The regulatory framework for the implementation of BIM technologies is currently at the stage of formation. Changes have been made to the Decree of the Government of the Russian Federation No. 87 "On the composition of sections of project documentation and requirements for their content", Decree of the Government of the Russian Federation No. 1431 approved the Rules for the formation and maintenance of information models. It is planned to complete the stage of creating classification tables in 2020.

Information modeling standards were developed and adopted: ISO 19650-1(2):2018 - a standard that describes the procedures for organizing data transfer. Similar standards are described in the NOPRIZ SP 328.1325800.2017 standards "Information Modeling in Construction. Rules for describing the components of the information model". Seven more documents on BIM standardization are in progress. They will be approved by the end of 2020 . These include the fundamental rulebooks that will define the elements of the digital model. All this necessitates both giving legal significance to the BIM model and ensuring clear interaction between construction companies, design institutions, government authorities and other participants in investment and construction projects (hereinafter: ICP).

There is still an important issue of assessing the effectiveness of the implementation of BIM technologies in the organization of design, construction and reconstruction of buildings, structures, facilities. Nowadays, the Government of the Russian Federation has developed and adopted an "Action Plan for the implementation of the economic efficiency assessment of investment justification and information modeling technologies at all stages of the life cycle of a capital construction object", No. 2468p-P9 dated April 11, 2017, which contains a list of measures on changes in regulatory legal acts in terms of assessing the effectiveness of investments in construction, taking into account the marginal cost of building an object and costs of its operation, demolition costs, as well as placement options. According to this document, the introduction of BIM technologies in the design, construction and reconstruction of buildings, structures, facilities should provide a reduction in design time, an increase in design automation, including the automated selection of design solutions, building materials, products, structures, the ability to manage the operation of capital construction facilities, taking into account the marginal operating costs, the ability to simulate the feasibility of investments, taking into account the costs of design, construction, operation and demolition of capital construction facilities. However, no clear and understandable criteria for the effectiveness of the implementation of BIM technologies in the design, construction and reconstruction of facilities have been developed, which is an urgent topic for research. Also, the issues of organizational interaction between the participants of the ICP remain relevant, which now operate on the basis of the system of organizing construction 
production that was established in Soviet times with the imposition of market relations on it and the digitalization of design and construction processes.

The basic principles of design consist in a combination of standard developments and individual solutions, taking into account the specific conditions of construction. The main tasks of the organization of construction are to interconnect the design and working documentation with the calendar and network schedules. Introduction of information modeling in these principles and tasks should be accompanied by clear and transparent criteria for the effective organization and management of investment and construction projects.

An investment and construction project is a complex system that unites the main participants in a construction project (customers, investors, designers, contractors) at the stages of design, construction (or reconstruction) of an object (building, structure, facility). Since these stages are interrelated, and the processes occur in parallel, the approaches to the management and organization of ICP are considered by the authors from the standpoint of a systematic approach detailed in [2].

One of the important features of the organization of construction production is that all participants in the investment and construction project pursue multidirectional interests (the customer wants to save money, the contractor - to make a profit, the designer also wants to make a profit and shorten the time). At the same time, there are restrictions in the form of legislation and technical regulations, and requirements for the implementation of information modeling technologies, which, for all their indisputable benefits, bring some chaos into the existing system of organizing design and construction, since different participants often use different software, contractors are often just don't know them, and it's expensive. There are problems associated with the transfer of data from various performers. Customers have to organize remote workstations and centers for collective use of BIM programs. As a result, time, money and quality of the object itself is lost. It takes a lot of time and money to resolve errors that arise from conflicts of interest. Therefore, an important scientific task is the development of such schemes for the organization and management of ICP, which would level conflicts, would allow the participants to achieve the values of target functions, and would work effectively in the context of the use of BIM technologies.

The complexity of modeling construction production when choosing options for construction and installation work is that these characteristics (terms; quality; resources, including cost; technology and organization of work) can be multidirectional: for example, a reduction in the terms of work can cause a decrease in their quality or an increase in cost due to the fact that additional resources are involved. Or a reduction in cost can lead to resource savings, but at the same time a loss in the quality of work and, as a result, a deterioration in the quality of the construction object itself can occur. Thus, it becomes necessary to conduct a detailed multivariate study and take into account the fact that the target functions of the models may turn out to be multidirectional.

The purpose of this study was to analyze modern modeling methods that allow describing the multidirectional interests of participants in an investment and construction project.

\section{Materials and methods}

Modern foreign research in the field of organization of construction production and information modeling is aimed at the development of work schedules, linking them with the developed BIM-models of construction objects [2]. In foreign publications, it is necessary to note a systematic approach to modeling construction processes, taking into account both the influence of construction and installation work on the characteristics of a construction object and the environment, and the influence of the entire life cycle of a building on the choice of options for construction and installation work [4]. Various modeling methods are applied: the Life Cycle Assessment (LCA) method, which is a systematic environmental 
management tool that holistically analyzes and evaluates the environmental impact of a product or process, outlined in the paper by Bilec, Ries and Matthew [5]. The paper states that in assessing the life cycle of a building, construction processes play not the main, but still a significant role. The offered by them model of the LCA structure is aggregated into eight main categories: site preparation, foundation construction, concrete work, wall masonry, metal frame construction, finishing works, transportation and handling, energy costs. This approach is justified by the fact that construction has many processes, and modeling each of them separately is not advisable.

Also, foreign scientists have developed simulation methods for large construction projects that are subject to external and uncontrolled events that affect their schedule and financial results. The authors of study [6] propose criteria for modeling large and complex systems, such as construction projects to support life cycle management, risk assessment and modeling of cyclical operations. For this they introduce the concept of "hybrid modeling", which includes a set of models: modeling networks by vertical (bottom-up and topdown) and horizontal (dependency/relation) to represent the hierarchy of building operations and companies; use of library elements concepts, agent philosophy, Monte Carlo analysis and discrete-event simulation (DES) with resource usage analysis and with queue and process calculation algorithm. The programming paradigm is object-oriented programming modified according to the agent-based modeling philosophy and automating the generation of modeling libraries and icons. Hybrid modeling provides lifecycle management: database import and export capabilities, and automation of data entry and documentation.

A lot of research by domestic and foreign scientists is devoted to the scheduling and network planning of construction and installation works, affecting various aspects of their planning and modeling. In [7], a model for planning construction activities with temporary connections is presented based on an algorithm for constructing a graphical work schedule, taking into account the problem of the correct sequence with the calculation of the "limited possible minimum" (LPM), which is a subject to technical and organizational constraints. In study [8], a linear programming model for the flow organization of construction is presented, which is aimed at the formation of linear graphs according to the criterion of the lowest cost of construction resources with restrictions on a possible reduction in construction time under the influence of risks and force majeure. In monograph [9], a CONSCOM neurodynamic model was created for the optimization of engineering design. It is a prototype of a software package for construction planning, cost optimization and change order management, which can be used by both owners and contractors to effectively manage construction projects, with the help of which repetitive and non-repetitive works were simulated, strategies of several construction organizations were developed, and the impact of different working conditions on their productivity was assessed. An optimization formulation of the problem of planning a construction project with the aim of minimizing direct construction costs is presented, which, due to its nonlinear nature, is solved using a neurodynamic model.

The authors of study [10] draw attention to the fact that the problem of construction planning and resource allocation is complex and has a stochastic nature. To solve it, it is proposed to introduce multi-object optimization, in which the project completion time and expected costs are minimized simultaneously. Biruk and Jaskowski propose planning construction using limited resource methods by creating a mathematical model for optimized planning of linear construction projects, taking into account resource constraints and continuity of work [11].

Among the domestic works on modeling construction production based on information modeling technologies, it is necessary to mention the studies of A.A. Volkov and his students on the possibility of using digitalization of information flows at all stages of construc- 
tion, taking into account the uncertainty of describing the construction process based on artificial intelligence systems [12]. And the works of A.A. Morozenko on the creation of a reflective-adaptive structure of investment and construction projects, D.V. Krasovsky on the application of the matrix of key project events in scheduling and network planning [13].

The analysis of modern methods of modeling construction production showed that the topic of maintaining a balance of interests of the participants in the ICP is currently insufficiently developed. This is especially important for large projects with many participants. At the same time, it becomes necessary to use information modeling technologies and a process approach, since BIM is, first of all, a process and business processes based on a BIM model. This is not a 3D static model with specification tables, but a process.

The development of the topic of modeling the balance of interests of ICP participants is of undoubted value both for theory and for the practice of organizing construction production. Modeling begins with the construction of target functions. Schematically, the objective functions and existing limitations can be shown as follows (Table 1).

Table 1. Target functions, limitations for participants in an investment and construction project

\begin{tabular}{|l|l|l|}
\hline \multicolumn{1}{|c|}{ ICP participants } & \multicolumn{1}{|c|}{ Target functions } & \multicolumn{1}{c|}{ Limitations } \\
\hline $\begin{array}{l}\text { Customer (wants the con- } \\
\text { struction or reconstruction } \\
\text { facility to be built and recon- } \\
\text { structed) }\end{array}$ & $\begin{array}{l}\text { Profit maximization, time sav- } \\
\text { ing, high quality of the facility, } \\
\text { commissioning of the facility } \\
\text { on time }\end{array}$ & $\begin{array}{l}\text { The need to organize the con- } \\
\text { nection of design and working } \\
\text { documentation. Time to con- } \\
\text { trol reporting. A pricing sys- } \\
\text { tem that does not involve } \\
\text { planning for reserves. }\end{array}$ \\
\hline $\begin{array}{l}\text { Designer (wants to prepare } \\
\text { project documentation on } \\
\text { time and get a positive expert } \\
\text { opinion) }\end{array}$ & $\begin{array}{l}\text { Profit maximization, minimiza- } \\
\text { tion of labor costs, meeting } \\
\text { design deadlines }\end{array}$ & $\begin{array}{l}\text { BIM model requirements. } \\
\text { Organization of examination } \\
\text { of design and estimate docu- } \\
\text { mentation. } \\
\text { Time to control reporting. }\end{array}$ \\
\hline $\begin{array}{l}\text { Contractor (wants to build the } \\
\text { facility on time and get an } \\
\text { estimated profit) }\end{array}$ & $\begin{array}{l}\text { Profit maximization, minimiza- } \\
\text { tion of time for organizing con- } \\
\text { struction (reconstruction) and } \\
\text { construction and installation } \\
\text { processes }\end{array}$ & $\begin{array}{l}\text { The need to develop working } \\
\text { documentation with construc- } \\
\text { tion (reconstruction) sched- } \\
\text { ules. Time to control report- } \\
\text { ing. A pricing system that } \\
\text { does not involve planning }\end{array}$ \\
\hline
\end{tabular}

The table shows that profit maximization is the main goal of all ICP participants, but this profit within the project is different for all participants: for the customer, it is the profit from the operation of the constructed object, and if there is a delay in the terms of its implementation, the customer's profit decreases. For a contractor, it is a profit from the execution of construction and installation work, and if the deadlines are delayed, collisions, unplanned reserves and other factors are revealed during the construction process, then his profit increases, since he gets more work. For a designer, the situation is similar: revision of project documentation brings additional profit.

Thus, the success of the ICP depends on the quality of planning, on the fact that at the time of planning, the ICP model includes non-compliance with deadlines, i.e. time reserves. It is also necessary to take into account that the emergence of complicated planning methods based on BIM technologies will lead to the need for additional costs for monitoring indicators. Besides, when planning an ICP using information modeling, it takes more time for additional resources: organizing a team, training to work in BIM programs, all this leads to additional overhead costs.

Modern methods of ICP management are aimed at achieving the set goals, among which the following can be identified: 
- Kanban - project management is seen as a set of processes superimposed on knowledge areas;

- $\quad$ PMBoK - the system of organization of production and supply, allowing implementation of the principle "just in time";

- Agile - flexible integrative-incremental approach to project and product management, focused on the dynamic formation of requirements and ensuring their implementation as a result of constant interaction within self-organizing working groups;

- ISO 21500 - principles and processes that are considered as constituents of rational project management activities.

However, no matter what approaches are in the basis, a necessary condition for achieving the goals of the ICP is the design of the organizational structure of the project as a complex system, especially since the introduction of BIM technology changes relations, processes, changes (mainly increases the number, since it becomes possible to increase the depth of development) a list of initial data, etc. These new opportunities and challenges lead to changes in the management model.

According to the authors, one of the most effective ICP management systems is a matrix structure: a vertical-horizontal balanced matrix (Figure 1). Such a structure integrates the features of a functional organizational structure with vertical management links (formed during the Soviet construction period) and a project management structure with horizontal technological links.

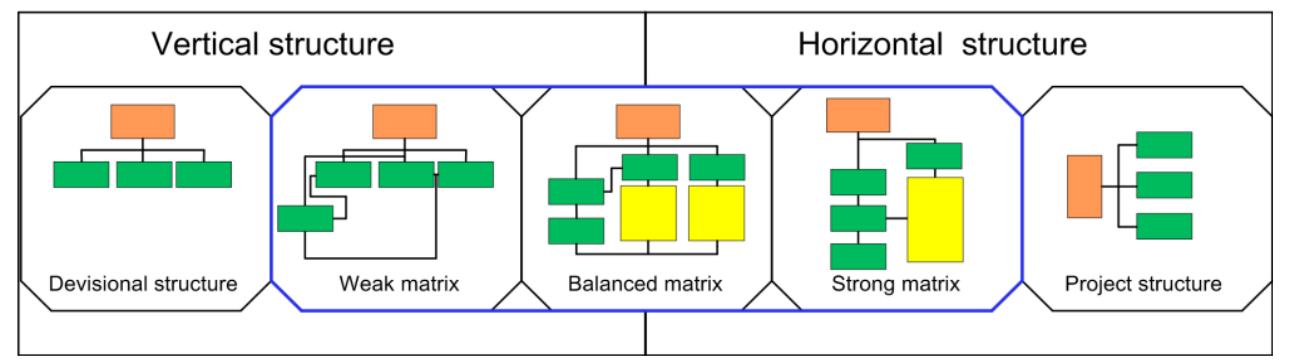

Fig. 1. Matrix structures of project management

The effectiveness of using a particular organizational structure depends on the content of the project, the goals of its participants, and on the requirements and restrictions imposed on the project by the external environment (use of BIM, pricing system, regulations, state examination requirements, etc.).

The development of an organizational structure for managing ICP, taking into account all the specified requirements, is a very complex methodological and poorly formalized task (the degree of formalization can be increased by using BIM technologies). In general, the relationship between the types of organizational structures in terms of content and level of structuring can be represented in the form of a diagram (Figure 2). 


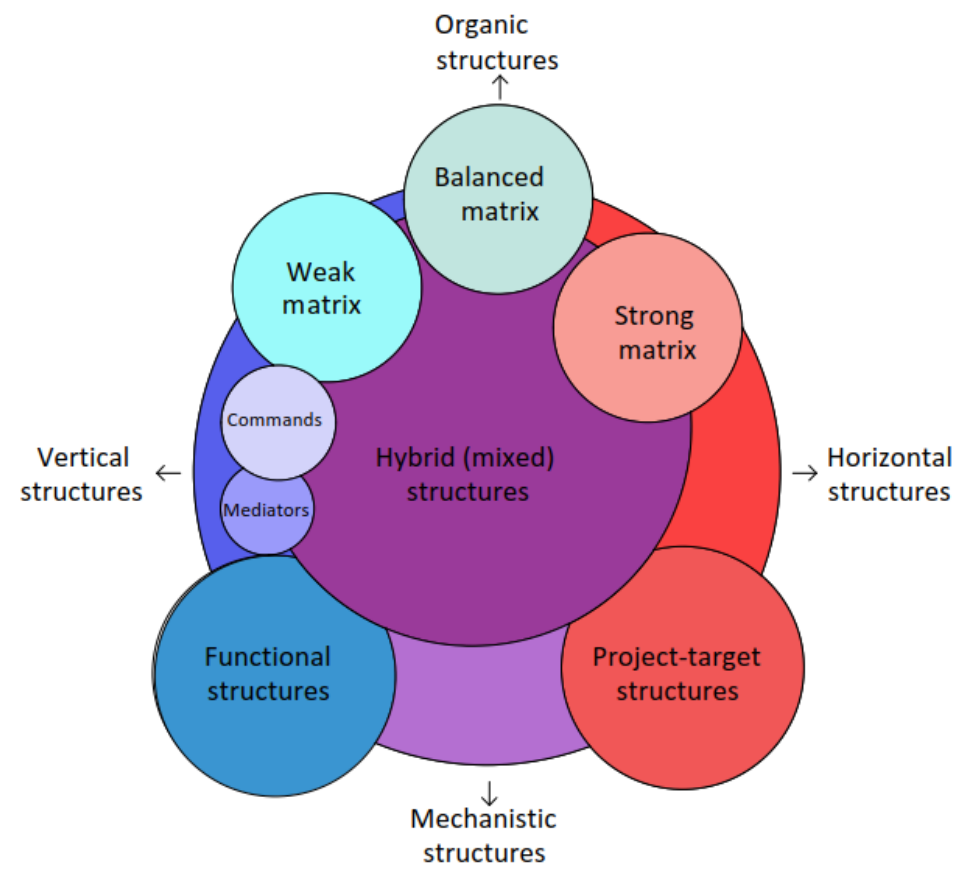

Fig. 2. Organizational structures in a two-dimensional space "direction of integration - level of structuring" (compiled by the authors based on [14])

In addition, there is a general dependence of the chosen organizational structure in terms of content and level of structuring on the system of relationships between project participants, expressed in the organizational structure diagram detailed in [14].

The important conditions in the design of matrix management structures for modern ICP are:

- the need to create reserves of time, since in the absence of reserves in the event of a conflict of resources, the solution of the issue requires escalation, and the matrix degenerates;

- horizontal interaction is necessary when simplifying management procedures and decision-making; vertical is necessary to resolve a number of issues at the top level, for example, when there are not enough resources to simultaneously execute company projects;

- resource planning: planned workload of personnel (no more than $70 \%$, the remaining time is needed to eliminate inevitable collisions);

- resolving issues with the modernization of the management of the company managing the project, issues of delegation of authority.

After the fundamental choice of the organizational structure, it is necessary to design it in detail, as well as model, especially for complex ICP, since modeling allows "playing" the interaction scenarios of project participants, working out business processes, and a preliminary assessment of their cost and effectiveness. Currently, the requirements for optimal organizational structures are becoming more and more complex, which causes the emergence of more and more advanced tools for multidimensional computer-aided design and modeling of the organization and management of ICP, allowing the creation of structures that include administrative links, horizontal processes, an information system, the structure of goals and objectives, production and technological infrastructure, socio-psychological aspects of the organization, and financial and economic indicators. 
According to the authors, the methodological apparatus for modeling the balance of interests of the ICP participants is game theory, namely, the Nash equilibrium, which, as applied to the ICP organization, can be formulated as follows: all ICP participants achieve their interests (win) without colluding [15]. Formally, the Nash equilibrium condition for modeling the balance of interests of ICP participants can be written as follows:

Let's consider an investment and construction project with a certain set of participants $N=\{1, \ldots, n\}$, as well as strategic sets $S_{1}, \ldots, S_{1}$ and payoff functions (achievement of the target by the $i$-th participant):

$$
U_{i}=S_{1} * \ldots * S_{1} \rightarrow R .
$$

The result of interaction $\left(S_{1}^{*}, \ldots, S_{n}^{*}\right)$ will be Nash equilibrium if $\forall i$ and $\forall S_{i} \in S_{i}$ (for any $i$-th participant and for any strategy that he could use), and the following condition is satisfied:

$$
U_{i}\left(S_{i}^{*}, S_{-i}^{*}\right) \geq U_{i}\left(S_{i}, S_{-i}^{*}\right),
$$

His gain (achievement of the target indicator) from the application of the prescribed strategy $S_{i}^{*}$, given that the rest of the participants apply precisely these prescribed strategies $\left(S_{1}^{*}, \ldots, S_{n}^{*}\right)$, will be no less than his gain from that situation, when he replaces his strategy with $S_{i}^{*}$, but the other participants will not replace anything.

In this way, the ICP management matrix remains balanced. In these conditions, automation of design and organization of construction, i.e. the use of BIM technologies, becomes an effective tool that allows maintaining the transparency of relations between the participants of the ICP and ensuring the progressive sustainable development of the construction industry.

\section{Results}

Summarizing the above, the authors consider it necessary to once again indicate that the development of a model for the balance of interests of ICP participants is becoming relevant. It is advisable to choose a matrix structure of ICP management, balanced by vertical and horizontal links. Appropriate methodological apparatus is the application of game theory. Information modeling technologies are instrumental support.

\section{Discussion}

Combining the meaning and significance of the results obtained, the authors have established that there are different goals of ICP participants, as well as a list of restrictions in the form of legislation and pricing policy. There is a tool in the form of BIM technologies. The introduction of BIM technologies has led to the need to change the organizational structures of investment and construction projects. In this regard, the adopted design and construction organization schemes are undergoing significant changes, including changes in the generally accepted system of organization and management of ICP. The first is to define goals: should BIM technologies lead to increased profits and by how much? Or should they lead to a reduction in costs and collisions that are discovered after checking the BIM model? This requires quantitative performance indicators for all participants in the investment and construction project: customer, designer, contractor. These requirements require a revision of the approach to the organization and management of investment and construction projects. 


\section{Conclusion}

Based on the above, the following conclusions are drawn:

1. The organizational environment must be such that the project management system can work.

2. It is necessary to refine the methodological base in order to make the process of organizing construction projects more manageable.

3. It is necessary to introduce quantitative criteria for assessing the effectiveness of ICP participants.

4. Clear criteria for the quality of the ICP organization are needed.

5. It is necessary to study the applied software products for project management and BIM technologies, in which design estimates and as-built documentation will be created.

6. Planning the reserves of time and resources is the most important key point in modeling the organizational structure of the ICP.

7. Modeling the balance of interests of the participants in the investment and construction process in the conditions of the use of BIM technologies to achieve the main goal: creating a high-quality construction object is becoming an urgent scientific task. At the same time, it is possible to create its digital twin (information model).

8. Game theory is a reasonable methodological tool for modeling the balance of interests of ICP participants.

\section{References}

1. I.S. Karasev, L.A. Oparina, Development of proposals for an action plan for the implementation of BIM technologies as a factor in the development of the Smart City concept, Young scientists - for the development of the National Technology Initiative (POISK-2020): collection of proceedings of the All-Russian (with international participation) youth scientific and technical conference. - Ivanovo: IVGPU 814, 270273 (2020)

2. L.A. Oparina, A systematic approach to organizing the life cycle of energy-efficient buildings, Housing construction 8, 12-15 (2014)

3. Lianying Zhang, Xiang Zhang, Teng Ma, Management of Construction Schedules Based on Building Information Modeling Technology, Emerging Technologies for Information Systems, Computing, and Management, 81-88 (2013)

4. Cormen, H. Thomas, Leiserson, E. Charles, Rivest, L. Ronald, Stein Clifford, Introduction to Algorithms (2nd Edition. Transl. from English, Williams Publishing house, M., 2010)

5. M. Bilec, R. Ries, Scott Matthews H., Life-Cycle Assessment Modeling of Construction Processes for Buildings, Journal of Infrastructure Systems 16(3), 199-205 (2010)

6. Mohamed Moussa, Y. Janaka, Ruwanpura, George Jergeas, and Tamer Mohamed. Hybrid Simulation Environment for Construction Projects: Identification of System Design Criteria, Journal of Construction Engineering, 12 (2014)

7. Zdzislaw Hejducki, Scheduling model of construction activity with time couplings, Journal of Civil Engineering and Management 9(4) 284-291 (2003)

8. Sławomir Biruk, Piotr Jaśkowski, Agata Czarnigowska, Updating Linear Schedules with Lowest Cost: a Linear Programming Model, IOP Conf. Series: Materials Science and Engineering, 245 (2017) 
9. Hojjat Adeli, Asim Karim, Construction scheduling, cost optimization, and management (Taylor \& Francis e-Library, 2005)

10. Qian Li, Sha Tao, Heap-Yih Chong, Zhijie Sasha Dong Robust, Optimization for Integrated Construction Scheduling and Multiscale Resource Allocation, Hindawi Complexity, 1-17 (2018)

11. S. Biruk, J. Jaskowski. Scheduling Linear Construction Projects with Constraints on Resource Availability, Archives of Civil Engineering 63(1), 3-15 (2017)

12. A.A. Volkova, F.K. Klashanov, P.B. Kagan, Digitalization in the management of information flows in construction. Construction systems engineering. Cyber-physical building systems - 2019, Collection of proceedings of the All-Russian scientific and practical conference, 81-85 (2019)

13. A.A. Morozenko, D.V. Krasovsky, Eliminating the shortcomings of scheduling and network planning by applying the matrix of key project events, Vestnik MGSU 12(6) (105), 674-679 (2017)

14. I.I. Mazur, V.D. Shapiro, N.G. Olderogge, Project management (Under the general edition of I.I. Mazur, 2nd ed., Omega-L, M., 2004)

15. V.S. Volkov, V.A. Yezhova, Game theory, Innovative technologies in science and education: collection of articles of the XII International scientific and practical conference, $155-158$ (2019) 